\title{
Effect of Egg Weight and Patio Strategies on Hatching Traits and Subsequent Performance of the Broilers
}

Original Article

-Author(s)

Yameen RMK' ID https://orcid.org/0000-0002-0603-6018 Hussain J' (D) https://orcid.org/0000-0002-4837-375X Mahmud A' (iD) https://orcid.org/0000-0002-2106-4113 Saimall (iD) https://orcid.org/0000-0003-2747-9691

Department of Poultry Production, Faculty of Animal Production \& Technology, University of Veterinary \& Animal Sciences, Lahore, 54000, Pakistan.

" Department of Animal Nutrition, Faculty of Animal Production \& Technology, University of Veterinary \& Animal Sciences, Lahore, 54000, Pakistan.

\section{-Mail Address}

Corresponding author e-mail address Rao Muhammad Kashif Yameen

Department of Poultry Production, Faculty of Animal Production \& Technology, University of Veterinary \& Animal Sciences, Lahore, 54000, Pakistan.

Phone: +92-302-7400023

Email: rkyameen@yahoo.com

\section{- Keywords}

Egg weight, Patio, hatch window, growth, welfare, blood biochemistry.

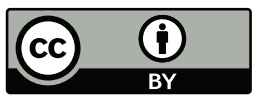

Submitted: 07/June/2020

Approved: 12/November/2020

\section{ABSTRACT}

Objectives of the present study were to assess the hatchery based interventions and their impact on hatching traits and subsequent performance of broilers. In total, 3000 eggs of Hubbard broiler breeders were equally divided into Small (50-55 g), Medium (56-61 g) and Large $(62-70 \mathrm{~g})$ eggs. The eggs from each category were distributed into 20 trays each containing 50 eggs. Each tray was considered as a replicate. At the end of the $18^{\text {th }}$ day of incubation, the eggs of each weight category were divided into four different patio strategies i.e. P0, P3, P5 and P7 where feed and water were provided to the chicks for 0 , 3,5 and 7 days in the hatcher followed by conventional rearing. Data were collected for hatch window, hatching traits, growth, physical asymmetry, welfare and blood profile in broilers. Statistical analysis showed that the smaller eggs had significantly $(\mathrm{P}<0.05)$ shorter hatch window compared to larger and medium eggs. Hatching traits were significantly $(p<0.05)$ better in medium eggs but the embryonic mortalities did not differ ( $p>0.05)$. The post-hatch performance was significantly $(p<0.05)$ better in P3 birds from medium eggs. Physical asymmetry and scores of feather and gait were not affected by both treatments ( $p>0.05)$. Blood profile was also significantly $(p<0.05)$ better in P3 birds from medium-size eggs. It was recommended that the eggs of 56-61g should be selected for better hatchability and the chicks should be provided with feed and water within the hatcher for at-least three days for optimum performance on rearing facility.

\section{INTRODUCTION}

Poultry production is one of the major industries fulfilling the protein requirement all over the world presenting 35\% of overall meat production (Statista, 2019). Among different segments of the poultry industry, broiler production is considered as an integral element of the agribusiness because the meat from broilers has a notable contribution in today's food consumption (Bell et al., 2002). The poultry business profitability is highly dependent on hatchery operations and on-farm management practices. Recent advances in broiler production have enabled the poultry producers to get the two kilograms live weight of the broilers within 35 days (Saxena \& Kolluri, 2018). But, this situation has led to the deterioration of many welfare and health-related traits. These problems are related to not only higher growth rate but also parent flock history (Saxena \& Kolluri, 2018). The on-farm practices have been so much optimized that there is very little or no choice to focus on other aspects of broilers' production. However, there is enough room to enhance the profitability by improving hatchery based operations and by facilitating the broilers with a better environment in early life. Egg weight has been reported to play a notable role in getting optimum 
Yameen RMK, Hussain J, Mahmud A, Saima
Effect of Egg Weight and Patio Strategies on Hatching Traits and Subsequent Performance of the Broilers

\section{Experimental design}

In total, 3000 eggs of Hubbard broiler breeders were procured from a commercial renowned breeder company and were divided into three weight categories i.e., Small (50-55 grams), Medium (56-61 grams) and Large (62-70 grams). The eggs from each category were distributed into 20 trays each having 50 eggs. Each tray was considered as a replicate. The egg trays were subsequently placed in the setter portion of the hatching machine (Victoria Incubator made in Italy) for 18 days. On the $18^{\text {th }}$ day, the eggs were candled and cleared eggs were removed and the eggs with embryonic growth were sent to the hatcher section. In the hatcher, the eggs of each weight category were divided into four different patio strategies that were designed for the chicks. Each patio strategy had five trays from each egg weight category. These patio strategies were:

Control = conventional hatching, no feed and water provision in the hatcher, transfer of the chicks to rearing shed at the end of the $21^{\text {st }}$ day of incubation.

P3 = provision of feed and water to the chicks for three days in the hatcher (18 to $21^{\text {st }}$ day of incubation, the temperature in hatcher $36.5^{\circ} \mathrm{C}$ ), then transfer to the rearing shed.

P5 = provision of feed and water to the chicks for five days in the hatcher (18 to $23^{\text {rd }}$ day of incubation, the temperature in the hatcher $36.5^{\circ} \mathrm{C}$ from 19 to $21^{\text {st }}$ day, $36^{\circ} \mathrm{C}$ at $22^{\text {nd }}, 35.5^{\circ} \mathrm{C}$ at $23^{\text {rd }}$ day), then transfer to the rearing shed.

P7 = provision of feed and water to the chicks for seven days in the hatcher (18 to $25^{\text {th }}$ day of incubation, the temperature in the hatcher was $36.5^{\circ} \mathrm{C}$ from 19 to $21^{\text {st }}$ day, $36^{\circ} \mathrm{C}$ at $22^{\text {nd }}, 35.5^{\circ} \mathrm{C}$ at $23^{\text {rd }}$ day, $35 \mathrm{C}$ at $24^{\text {th }}$ and 34.5 at $25^{\text {th }}$ day), then transfer to the rearing shed.

\section{Post-hatch management of the birds}

Chicks obtained in each patio strategy from each egg weight category were sent to the rearing facility after they completed the assigned duration in the hatcher. The rearing shed was furnished with replication units made of stainless steel wire. The chicks were kept according to $3 \times 4$ factorial arrangement and each experimental unit had separate manual feeders. The water was provided with nipple drinking systems. The initial brooding temperature was maintained at $33^{\circ} \mathrm{C}$ until the $10^{\text {th }}$ day of the birds' age. Gradually, the temperature of the house was reduced on a daily basis to $26^{\circ} \mathrm{C}$ with the advancement of the age. Broiler starter (day 1 to day 10), grower (day 11 to 22) and 
finisher (23 to 35 days of age) diets were offered to the birds ad-libitum (Table 1). Vaccination of the birds was performed following the recommendations of the Pakistan Poultry Association (Table 2).

Table 1 - Ingredient composition of rations for experimental birds.

\begin{tabular}{|c|c|c|c|c|c|c|c|c|}
\hline Ingredients & Starter & Grower & Finisher & Premix & Unit /kg & Starter & Grower & Finisher \\
\hline Maize & 61.03 & 63.29 & 63.99 & A & IU & 11000 & 10000 & 9000 \\
\hline Soybean Meal 46\% & 36 & 33.72 & 30.92 & D3 & IU & 5000 & 4500 & 3600 \\
\hline Soybean oil & -- & 0.32 & 2.68 & $E$ & $\mathrm{mg}$ & 25 & 20 & 20 \\
\hline Lime stone & 1.06 & 0.96 & 0.84 & K & $\mathrm{mg}$ & 3.2 & 3.0 & 2.2 \\
\hline $\mathrm{MCP}$ & 0.36 & 0.22 & 0.1 & B1 & $\mathrm{mg}$ & 3.2 & 3.0 & 2.2 \\
\hline Salt & 0.3 & 0.3 & 0.3 & B2 & $\mathrm{mg}$ & 8.0 & 6.5 & 5.4 \\
\hline DLM & 0.29 & 0.27 & 0.24 & Pyridoxin & $\mathrm{mg}$ & 4 & 3 & 2 \\
\hline L-Lysine Hcl & 0.23 & 0.24 & 0.24 & B12 & $\mathrm{mg}$ & 0.016 & 0.011 & 0.011 \\
\hline L-therionine & 0.09 & 0.08 & 0.08 & Folic acid & $\mathrm{mg}$ & 1.4 & 1.4 & 1.4 \\
\hline Sodabicarconate & 0.15 & 0.15 & 0.15 & Pantothenate & $\mathrm{mg}$ & 12 & 10 & 8 \\
\hline Choline Chloride 60\% & 0.07 & 0.03 & 0.04 & Niacin & $\mathrm{mg}$ & 55 & 50 & 45 \\
\hline Phytase & 0.02 & 0.02 & 0.02 & Biotin & $\mathrm{mg}$ & 0.20 & 0.16 & 0.12 \\
\hline Premix & 0.4 & 0.4 & 0.4 & Copper & $\mathrm{mg}$ & 18 & 18 & 18 \\
\hline Crude Protein & 22.09 & 21.2 & 20 & Ferous & $\mathrm{mg}$ & 50 & 50 & 50 \\
\hline \multirow[t]{4}{*}{ Metabolizable Energy (Kcal/Kg) } & 2872 & 2930 & 3090 & Manganese & $\mathrm{mg}$ & 120 & 120 & 120 \\
\hline & & & & Zinc & $\mathrm{mg}$ & 100 & 100 & 100 \\
\hline & & & & lodine & $\mathrm{mg}$ & 1.1 & 1.1 & 1.1 \\
\hline & & & & Selenium & $\mathrm{mg}$ & 0.3 & 0.3 & 0.3 \\
\hline
\end{tabular}

Table 2 - Vaccination schedule of experimental birds.

\begin{tabular}{lcc}
\hline Day & Vaccine & Rout of Administration \\
\hline 0 (at hatchery) & ND + IB & Sub cut \\
7 & ND & Eye Drop \\
13 & IBD & Drinking Water \\
18 & ND & Drinking Water \\
\hline
\end{tabular}

\section{PARAMETERS EVALUATED}

\section{Hatch window and hatching traits}

Hatch window was calculated in hours by noting the complete hatch time of each treatment. For egg weight/moisture loss, eggs were weighed on the $1^{\text {st }}$ and $18^{\text {th }}$ day of incubation and difference was termed as egg weight/moisture loss. The break-out analysis was done after the completion of the hatch window, and dead germs, dead in shells, total chicks obtained, culled chicks, and chicks with no defects were counted. Their results were presented in percentage of total eggs sett. Fertility \% was derived by dividing the total fertile eggs (sum of total chicks, dead germs and dead in shells) with the total eggs sett. Hatch of fertile was calculated by dividing the total hatched chicks by total fertile eggs. Chick weight of each treatment was calculated by measuring $10 \%$ of the sample using a weighing scale which can measure up to $0.01 \mathrm{gm}$.

\section{Post-hatch growth performance}

In growth performance, daily feed intake was calculated by using the following formula.

Feed intake $(\mathrm{g})=$ Feed offer $(\mathrm{g})-$ Feed refusal $(\mathrm{g})$
Body weight of the birds was calculated on a weekly basis by using a weighing scale (Company name) which can weigh up to $0.5 \mathrm{~g}$.

Body weight gain $(\mathrm{g})=$ Finale weight $(\mathrm{g})-$ initial weight (g)

The feed conversion ratio was calculated on a weekly basis till the market day ( $35^{\text {th }}$ day) of bird, by using the following formula.

$$
\mathrm{FCR}=\frac{\text { Feed consumed }(\mathrm{g})}{\text { Body weight }(\mathrm{g})}
$$

Livability was noted on the $35^{\text {th }}$ day by the following formula.

$$
\text { Livability } \%=\frac{\text { no. of birds placed }}{\text { no. of live birds }} \times 100
$$

\section{Welfare Traits}

Welfare parameters were assessed on 15 birds (35 days old) from each replicate and an average value was used for statistical analysis. Feather scores were assigned from 0-2 ( $0=$ no feather loss: $1=$ moderate feather loss: $2=$ severe feather loss) following the Welfare Poultry Protocol of the Netherland. For gait scoring, walking the birds for five feet was assessed for any signs of lameness and score was assigned from 0 to 2 where $0=$ perfect, $1=$ obvious signs and $2=$ severe signs of lameness.

\section{Physical asymmetry}

Physical asymmetry of 05 birds per replicate was measured as per Archer et al. (2009) on the $35^{\text {th }}$ day 
Yameen RMK, Hussain J, Mahmud A, Saima
Effect of Egg Weight and Patio Strategies on Hatching Traits and Subsequent Performance of the Broilers of age. For this purpose, metatarsal length, width and middle toe length $(\mathrm{mm})$ were measured of both left $(\mathrm{L})$ and right ( $\mathrm{R}$ ) legs, by using Vernier Caliper. The composite asymmetry score was calculated by taking the sum of the absolute value of the left minus the right of each trait, then dividing by the total number of traits.

Composite asymmetry score $=\frac{\{L-R(m t)\}+\{L-R(m l)\}+\{L-R(m w)\}}{3}$

$$
\begin{aligned}
& \text { Where, } \\
& \mathrm{mtl}=\text { Middle toe length }(\mathrm{mm}) \\
& \mathrm{ml}=\text { Metatarsal length }(\mathrm{mm}) \\
& \mathrm{mw}=\text { Metatarsal width }(\mathrm{mm}) \\
& \text { No. of traits }=3
\end{aligned}
$$

\section{Blood biochemical profile}

On the $35^{\text {th }}$ day of age, blood samples of $2 \mathrm{ml}$ each were collected from four birds per replicate to study blood metabolites. These samples were sent to the University Diagnostic Laboratory, UVAS, Lahore, Pakistan where the samples were analyzed using commercially available specific kits for, glucose (mmol/L), total protein $(\mathrm{g} / \mathrm{dL})$, albumin $(\mathrm{g} / \mathrm{dL})$, globulin $(\mathrm{g} / \mathrm{dL})$, uric acid $(\mathrm{mg} / \mathrm{dL})$, cholesterol $(\mathrm{mg} / \mathrm{dL})$ and creatinine $(\mathrm{mg} / \mathrm{dL})$.

\section{Statistical Analysis}

Data for hatch window and hatching traits were analyzed through one-way ANOVA using SAS software and significant treatment means were separated through Least Significant difference test by assigning the egg weight categories as a source of treatment. Post-hatch growth performance, livability, welfare traits, physical asymmetry and blood biochemical profile were analyzed through factorial ANOVA (twoway analysis of variance) by assigning egg weight categories and patio strategies as the main effect and significant means were compared through Duncan's Multiple Range test (Duncan, 1955).

\section{RESULTS}

\section{Hatch window}

Figure 1 describes the overall hatching pattern for small, medium and large-sized eggs under study. It is clear from the figure that the small-sized eggs hatched more at 471 hours $(p<0.05)$ compared to mediumsized eggs and took significantly less time for hatch completion. Maximum hatchability was noted at 491 hours post-placement in setter in small eggs compared to larger eggs $(p<0.05)$. On an overall basis, medium and larger sized eggs took significantly more time than small-sized eggs as shown in figure 1, which shows that the chicks from medium and large-sized eggs were yet to come even after 504 hours $(p<0.05)$.

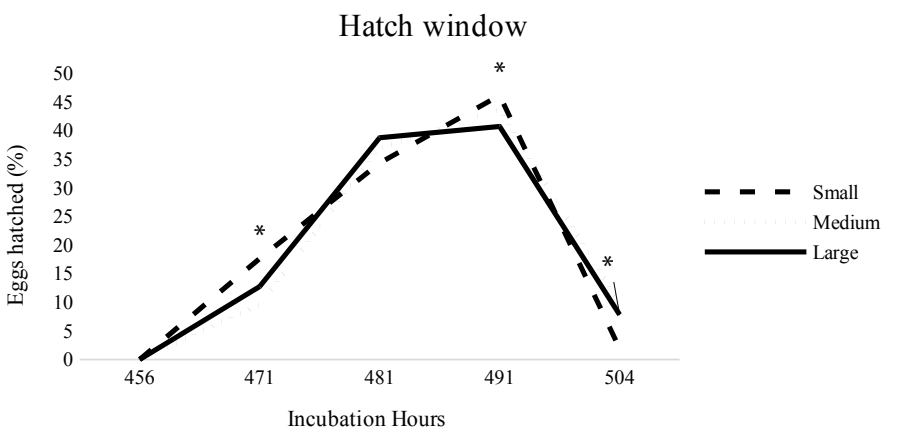

Figure 1 - Hatch window of different egg weight categories in broiler breeder. *Shows the significant differences among small, medium and larger size eggs.

\section{Hatching traits}

Table 3 shows the mean values of egg weight loss and hatching traits of broiler breeder's eggs of different weight categories. Statistical analysis showed a significant impact of egg weight on egg weight loss and most of the hatching traits $(p<0.05)$ except embryonic mortalities. Medium-sized eggs encountered with a significantly higher loss $(10.16 \pm 0.21)$ compared to large-sized eggs $(9.10 \pm 0.16)$. However, the weight loss in small eggs $(9.70 \pm 0.37)$ was not significantly different from medium and large eggs ( $p>0.05$ ). Hatchability $\%$ was significantly higher in medium-sized eggs $(89.60 \pm 1.27)$ compared to large eggs $(81.70 \pm 2.35)$ whereas the small eggs' hatchability $(86.10 \pm 1.57)$ was comparable to both the medium and large size eggs. A similar trend was observed for fertility results where medium-sized eggs were more fertile $(97.70 \pm 0.68)$ than larger eggs $(94.00 \pm 0.95)$ and small-sized eggs $(96.20 \pm 0.74)$ were non-significantly different from medium and large-sized eggs. On the other hand, the hatch of fertile was similar among all three egg weight categories $(p>0.05)$. Moreover, embryonic mortality patterns (early, mid and late mortalities) were not different among the experimental egg weight groups. Culled chicks were significantly higher in larger eggs $(2.08 \pm 0.88)$ than medium-sized eggs $(0.00 \pm 0.00)$, however, smaller sized eggs produced a comparable number of culled chicks $(0.61 \pm 0.31)$ to that of medium and large size eggs. The number of chicks with no defects was significantly higher in mediumsized eggs (100.00 \pm 0.00$)$ compared to large eggs (97.92 \pm 0.88$)$ while small eggs produced a comparable number of defect-less chicks $(99.39 \pm 0.31)$ to that of medium and larger eggs. There was a significant effect of egg weight on the weight of the chicks $(p<0.05)$. 
Larger sized eggs produced significantly heavier chicks $(44.27 \pm 0.40)$ than medium-sized eggs $(41.78 \pm 0.28)$ and the lowest chick weight was noted in small-sized eggs $(38.40 \pm 0.28)$.

Table $\mathbf{3}$ - Hatching traits as affected by different egg weights.

\begin{tabular}{|c|c|c|c|c|c|c|c|c|c|c|}
\hline E. Wt. & E.Wt. loss & Hatch & HOF & Fertility & $\begin{array}{l}\text { EEM } \\
(\%)\end{array}$ & MEM & LEM & Cull & No defect & $\begin{array}{c}\text { Chick Wt } \\
(\mathrm{g})\end{array}$ \\
\hline Small & $9.70 \pm 0.37^{\mathrm{ab}}$ & $86.10 \pm 1.57^{\mathrm{ab}}$ & $89.40 \pm 1.10$ & $96.20 \pm 0.74^{\mathrm{ab}}$ & $4.00 \pm 0.50$ & $2.50 \pm 0.54$ & $4.00 \pm 0.71$ & $0.61 \pm 0.31^{\mathrm{ab}}$ & $99.39 \pm 0.31^{\mathrm{ab}}$ & $38.40 \pm 0.28^{c}$ \\
\hline Medium & $10.16 \pm 0.21^{\mathrm{a}}$ & $89.60 \pm 1.27^{a}$ & $91.68 \pm 0.98$ & $97.70 \pm 0.68^{a}$ & $4.00 \pm 0.58$ & $2.50 \pm 0.81$ & $4.50 \pm 1.18$ & $0.00 \pm 0.00^{b}$ & $100.00 \pm 0.00^{a}$ & $41.78 \pm 0.28^{b}$ \\
\hline Large & $9.10 \pm 0.16^{b}$ & $81.70 \pm 2.35^{b}$ & $86.81 \pm 2.08$ & $94.00 \pm 0.95^{b}$ & $3.40 \pm 0.54$ & $2.50 \pm 0.79$ & $5.50 \pm 1.00$ & $2.08 \pm 0.88^{a}$ & $97.92 \pm 0.88^{b}$ & $44.27 \pm 0.40^{a}$ \\
\hline$p$-value & 0.0217 & 0.0108 & 0.0731 & 0.0070 & 0.6681 & 1.000 & 0.5504 & 0.0241 & 0.0241 & $<0.0001$ \\
\hline
\end{tabular}

E.Wt is egg weight; Hatch is hatchability; HOF is hatch of fertile; EEM is early embryonic mortality; MEM is mid embryonic mortality; LEM is late embryonic mortality; Chick Wt is chick weight.

\section{Post-hatch growth performance}

Statistical analysis showed that the feed intake of the broilers (Table 4) was significantly affected by egg size $(p<0.05)$. The birds from small eggs consumed significantly less feed $(3337.81 \pm 22.81)$ than those from medium (3475.88 \pm 45.23$)$ and large eggs

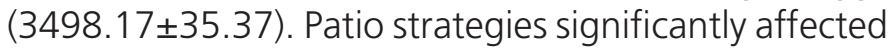
the feed intake of the birds. Minimum feed intake (3354.17 \pm 26.40$)$ was noted when the birds were conventional hatching practice i.e control (P0) whereas maximum feed consumption $(3528.44 \pm 54.50)$ was recorded when the birds provided feed and water for five days inside the hatcher (P5). Concerning interactions, the lowest feed intake was found in the birds from the smaller eggs reared under PO $(3341.29 \pm 26.95)$ while the highest feed intake was noted in the birds from the medium-sized eggs subjected to P5 (3662.33 \pm 111.20$)$.

Broilers' body weight gain was also affected significantly $(p<0.05)$ by the egg weight (Table 4$)$. The birds from medium and larger size eggs gained significantly higher weight $(2139.99 \pm 31.66)$ than the birds from the small-size eggs $(2024.33 \pm 15.87)$. Patio strategies significantly affected the body weight gain of the birds. The birds under P3 had significantly higher

Table 4 - Growth performance and livability of broilers from three different egg weight categories reared under different patio strategies.

\begin{tabular}{|c|c|c|c|c|}
\hline & F.I & B.W.G & FCR & Livability \\
\hline \multicolumn{5}{|l|}{ Egg Wt } \\
\hline Small & $3337.81 \pm 22.81^{\mathrm{b}}$ & $2024.33 \pm 15.87^{b}$ & $1.65 \pm 0.01^{b}$ & $92.51 \pm 1.00$ \\
\hline Medium & $3475.88 \pm 45.23^{a}$ & $2139.99 \pm 31.66^{a}$ & $1.63 \pm 0.01^{c}$ & $92.68 \pm 0.94$ \\
\hline Large & $3498.17 \pm 35.37^{a}$ & $2090.27 \pm 27.63^{a}$ & $1.68 \pm 0.01^{\mathrm{a}}$ & $93.60 \pm 0.66$ \\
\hline$p$-value & 0.0016 & 0.0021 & $<.0001$ & 0.1547 \\
\hline \multicolumn{5}{|l|}{ Patio strategy } \\
\hline PO & $3354.17 \pm 26.40^{b}$ & $2004.87 \pm 16.31^{b}$ & $1.67 \pm 0.01^{\mathrm{a}}$ & $90.92 \pm 0.49^{c}$ \\
\hline P3 & $3460.98 \pm 48.26^{a b}$ & $2144.60 \pm 34.20^{a}$ & $1.61 \pm 0.01^{c}$ & $94.81 \pm 0.51^{b}$ \\
\hline P5 & $3528.44 \pm 54.50^{a}$ & $2144.30 \pm 37.06^{a}$ & $1.65 \pm 0.01^{b}$ & $96.34 \pm 0.34^{a}$ \\
\hline P7 & $3405.57 \pm 33.93^{b}$ & $2045.68 \pm 20.23^{b}$ & $1.66 \pm 0.01^{\mathrm{ab}}$ & $89.64 \pm 1.23^{c}$ \\
\hline$p$-value & 0.0113 & 0.0002 & $<.0001$ & $<.0001$ \\
\hline \multicolumn{5}{|l|}{ Interaction } \\
\hline Small×PO & $3341.29 \pm 26.95^{d}$ & $1994.07 \pm 22.21^{c}$ & $1.68 \pm 0.01^{\mathrm{abc}}$ & $91.52 \pm 0.99^{\text {cd }}$ \\
\hline SmallxP3 & $3294.16 \pm 20.46^{d}$ & $2034.96 \pm 28.19^{c}$ & $1.62 \pm 0.02^{\mathrm{de}}$ & $94.88 \pm 0.83^{\mathrm{ab}}$ \\
\hline SmallxP5 & $3357.95 \pm 67.57^{\mathrm{cd}}$ & $2040.63 \pm 47.29^{c}$ & $1.65 \pm 0.01^{\mathrm{bcd}}$ & $97.07 \pm 0.50^{\mathrm{a}}$ \\
\hline Small×P7 & $3357.86 \pm 59.13^{\mathrm{cd}}$ & $2027.66 \pm 30.52^{c}$ & $1.66 \pm 0.01^{\mathrm{bcd}}$ & $86.57 \pm 1.19^{e}$ \\
\hline Medium $\times$ PO & $3311.40 \pm 28.17^{d}$ & $2023.19 \pm 19.12^{c}$ & $1.64 \pm 0.01^{\mathrm{cd}}$ & $91.70 \pm 0.73^{\mathrm{cd}}$ \\
\hline Medium $\times$ P3 & $3492.65 \pm 50.12^{\mathrm{abcd}}$ & $2202.46 \pm 50.36^{a b}$ & $1.59 \pm 0.02^{\mathrm{e}}$ & $95.88 \pm 0.77^{\mathrm{ab}}$ \\
\hline Medium $\times$ P5 & $3662.33 \pm 111.20^{a}$ & $2255.57 \pm 67.89^{a}$ & $1.62 \pm 0.00^{\mathrm{ed}}$ & $96.16 \pm 0.42^{\mathrm{ab}}$ \\
\hline Medium×P7 & $3437.15 \pm 85.47^{\mathrm{bcd}}$ & $2078.72 \pm 53.58^{\mathrm{bc}}$ & $1.65 \pm 0.01^{\mathrm{bcd}}$ & $86.99 \pm 1.23^{e}$ \\
\hline LargexPO & $3409.82 \pm 67.25^{\mathrm{bcd}}$ & $1997.35 \pm 42.51^{c}$ & $1.71 \pm 0.01^{\mathrm{a}}$ & $89.54 \pm 0.48^{d}$ \\
\hline LargexP3 & $3596.13 \pm 98.73^{\mathrm{ab}}$ & $2196.38 \pm 66.61^{a b}$ & $1.64 \pm 0.02^{\mathrm{cd}}$ & $93.69 \pm 0.91^{b c}$ \\
\hline LargexP5 & $3565.03 \pm 46.57^{\mathrm{abc}}$ & $2136.69 \pm 42.17 \mathrm{abc}$ & $1.67 \pm 0.03^{\mathrm{abc}}$ & $95.80 \pm 0.76^{\mathrm{ab}}$ \\
\hline LargexP7 & $3421.70 \pm 20.13^{\mathrm{bcd}}$ & $2030.67 \pm 9.26^{c}$ & $1.69 \pm 0.01^{\mathrm{ab}}$ & $95.35 \pm 0.80^{\mathrm{ab}}$ \\
\hline$p$-value & 0.0014 & 0.0002 & $<.0001$ & $<.0001$ \\
\hline
\end{tabular}

Fl is feed intake; BWG is body weight gain; FCR is feed conversion ratio; $\mathrm{PO}$ is patio feeding for 0 day; $\mathrm{P} 3$ is patio feeding for 3 days; $\mathrm{P} 5$ is patio feeding for 5 days; $\mathrm{P7}$ is patio feeding for 7 days. 
weight gain $(2144.60 \pm 34.20)$ whereas the birds under P0 showed the lowest gain in weight (2004.87 \pm 16.31$)$. Significant interactions among egg weight and patio strategies were also noted for body weight gain. When the broiler chicks from the medium-sized eggs were reared under P5 they presented the highest weight gain (2255.57 \pm 67.89$)$ while the birds from the smallsized eggs reared under conventional hatching had the lowest weight gain (1994.07 \pm 22.21$)$.

When FCR was compared, significant variations $(p<0.05)$ were noted among the birds from three egg weight categories (Table 4). Overall FCR was better in the broilers from medium-sized eggs $(1.63 \pm 0.01)$ followed by those from smaller eggs $(1.65 \pm 0.01)$ and the poor FCR was recorded for those from the larger eggs (1.68 \pm 0.01$)$. Patio strategy significantly impacted the FCR of the birds $(p<0.05)$. FCR of the birds under P3 was better $(1.61 \pm 0.01)$ followed by those under P5 $(1.65 \pm 0.01)$ and the poor FCR $(1.67 \pm 0.01)$ was noted in the birds under conventional hatching system i.e PO. Regarding interaction, the birds from medium-size eggs reared under P3 showed better FCR $(1.59 \pm 0.02)$ whereas the birds from the larger eggs under PO showed poor FCR $(1.71 \pm 0.01)$ among all the possible interactions.

\section{Livability}

Egg weight did not exert any impact on livability percentage $(p>0.05)$ of the birds. However, patio strategies resulted in significant differences in the livability of the birds (Table 4). The birds under P5 survived more $(96.34 \pm 0.34 \%)$ followed by P3 and the least survival rate was recorded in the birds under P7 (89.64 \pm 1.23$)$. Livability differed significantly when the interactions among the egg weight categories and patio strategies were evaluated. The broilers from the smaller eggs reared under P5 showed the highest livability $(97.07 \pm 0.50)$ whereas the birds from small egg size under $\mathrm{P7}$ had the lowest survival rate (86.57 \pm 1.19 ).

\section{Physical asymmetry and welfare traits}

Statistical analysis showed no effect ( $p>0.05)$ of egg weight and patio strategies on physical asymmetry and gait scores of the broilers (Table 5). However, feather score significantly differed among the broilers from different egg weight categories $(p<0.05)$. The birds from the larger eggs had significantly cleaner feathers (lower feather score, $0.18 \pm 0.00$ ) than those from the medium-sized eggs which had dirty feathers and showed poor feather score $(0.47 \pm 0.07)$. Patio strategies did not affect the feather score $(p>0.05)$.
However, egg weight significantly interacted with patio strategies $(p<0.05)$. The chicks from small and large size eggs, when provided with feed and water for seven days within the hatcher (P7), had cleaner feathers with adequate feather cover than any other treatment both showing the lowest feather scores $(0.00 \pm 0.00)$. On the other hand, the birds from the medium-sized eggs under conventional hatching and rearing process (P0) showed a poor feather score $(0.80 \pm 0.14)$.

Table 5 - Effect of egg weight and patio strategies on physical asymmetry and welfare traits of broilers.

\begin{tabular}{|c|c|c|c|}
\hline & $\begin{array}{c}\text { Physical } \\
\text { asymmetry }\end{array}$ & Gait Score & Feather Score \\
\hline \multicolumn{4}{|l|}{ Egg weight } \\
\hline Small & $0.42 \pm 0.29$ & $0.42 \pm 0.07$ & $0.37 \pm 0.07^{a b}$ \\
\hline Medium & $0.26 \pm 0.28$ & $0.35 \pm 0.06$ & $0.47 \pm 0.07^{a}$ \\
\hline Large & $-0.34 \pm 0.34$ & $0.33 \pm 0.07$ & $0.18 \pm 0.0^{b}$ \\
\hline$p$-value & 0.1793 & 0.6429 & 0.0049 \\
\hline \multicolumn{4}{|c|}{ Patio strategies } \\
\hline PO & $0.17 \pm 0.41$ & $0.36 \pm 0.07$ & $0.31 \pm 0.08$ \\
\hline P3 & $0.12 \pm 0.32$ & $0.47 \pm 0.09$ & $0.40 \pm 0.08$ \\
\hline P5 & $-0.13 \pm 0.34$ & $0.29 \pm 0.07$ & $0.40 \pm 0.08$ \\
\hline P7 & $0.28 \pm 0.34$ & $0.36 \pm 0.07$ & $0.24 \pm 0.06$ \\
\hline$p$-value & 0.8634 & 0.4301 & 0.3337 \\
\hline \multicolumn{4}{|l|}{ Interaction } \\
\hline Small×PO & $0.68 \pm 0.73$ & $0.40 \pm 0.13$ & $0.53 \pm 0.17^{a b}$ \\
\hline Small×P3 & $0.59 \pm 0.59$ & $0.40 \pm 0.13$ & $0.40 \pm 0.13^{b}$ \\
\hline SmallxP5 & $-0.76 \pm 0.78$ & $0.27 \pm 0.12$ & $0.00 \pm 0.00^{c}$ \\
\hline Small×P7 & $-0.27 \pm 0.40$ & $0.47 \pm 0.17$ & $0.20 \pm 0.11^{b c}$ \\
\hline Medium $\times$ PO & $0.49 \pm 0.60$ & $0.40 \pm 0.13$ & $0.80 \pm 0.14^{a}$ \\
\hline Medium $\times$ P3 & $0.15 \pm 0.65$ & $0.53 \pm 0.17$ & $0.20 \pm 0.11^{c}$ \\
\hline Medium $\times$ P5 & $0.73 \pm 0.53$ & $0.33 \pm 0.13$ & $0.33 \pm 0.13^{b c}$ \\
\hline Medium×P7 & $0.25 \pm 0.61$ & $0.27 \pm 0.12$ & $0.33 \pm 0.13^{b c}$ \\
\hline LargexPO & $-1.37 \pm 0.53$ & $0.27 \pm 0.12$ & $0.53 \pm 0.17^{a b}$ \\
\hline LargexP3 & $0.52 \pm 0.60$ & $0.47 \pm 0.13$ & $0.40 \pm 0.13^{b}$ \\
\hline LargexP5 & $-0.29 \pm 0.40$ & $0.33 \pm 0.13$ & $0.33 \pm 0.13^{b c}$ \\
\hline LargexP7 & $0.63 \pm 0.72$ & $0.27 \pm 0.12$ & $0.00 \pm 0.00^{c}$ \\
\hline$p$-value & 0.1880 & 0.9483 & 0.0013 \\
\hline
\end{tabular}

Different superscript within a column show significant differences.

\section{Blood biochemical profile}

Table 4 shows the mean values of glucose, total protein, albumin, globulin, uric acid, cholesterol and creatinine. Statistical analysis showed significant $(p<0.05)$ impact of egg weight and patio strategies on the blood glucose levels of broilers (Table 6). Higher glucose contents were noted in the birds from large eggs $(13.63 \pm 0.52)$ while the lower glucose was observed in the blood of the birds from the medium eggs (11.08 \pm 0.48$)$. Among the patio treatments, significantly higher glucose level was observed in the birds from P7 group (14.95 \pm 0.60$)$ that was nonsignificantly different from P5 and the lower glucose was noted in P0 (10.28 0.40$)$ that was non-significant to P3. A significant interaction was noted among the 
egg weight and patio strategies $(p<0.05)$. Highest glucose in broilers $(16.05 \pm 1.02)$ was recorded when the chicks from the large eggs were offered feed and water inside the hatcher for seven days (P7). While small $\times$ P3 treatment presented the lowest glucose contents $(8.30 \pm 0.54)$ than any other experimental group.

There was no effect of egg weight categories and patio strategies, nor was any interaction on total protein contents in the blood of the broilers $(p>0.05)$. There was a significant influence $(p<0.05)$ of egg weight and patio strategies on albumin contents of the broilers. Significantly higher albumin was found in the broilers from large eggs $(1.45 \pm 0.03)$ compared to those from medium eggs $(1.36 \pm 0.03)$. Among the feeding strategies, providing the chicks with feed and water inside the hatcher for seven days (P7), resulted in significantly higher blood albumin contents $(1.49 \pm 0.04)$ whereas the birds from conventional routine practice (PO) were lowest in this parameter (1.27 \pm 0.03$)$. Regarding interaction, significantly highest albumin contents $(1.64 \pm 0.04)$ were noted in the birds from larger eggs $(p<0.05)$ and P0 group and the lowest glucose $(1.20 \pm 0.06)$ was recorded when the chicks from the small eggs were kept in the hatcher for three days (P3). Regarding globulin, egg weight and patio strategies resulted in non-significant differences in blood globulin contents of the broilers. However, there was significant interaction $(p<0.05)$ showing the highest contents of globulin $(2.08 \pm 0.17)$ in the broilers from medium eggs and $\mathrm{P7}$ patio strategy and the lowest $(1.31 \pm 0.13)$ were found in the bids from large eggs and P7 group. There was a significant effect of egg size and patio strategies on blood uric acid. Among the egg categories, the birds from the larger eggs had significantly $(p<0.05)$ higher uric acid contents $(3.52 \pm 0.09)$ in their blood compared to those from the smaller eggs $(3.23 \pm 0.08)$. In terms of patio strategies, P7 group presented the highest contents of uric acid $(4.05 \pm 0.06)$ while the birds from PO had the lowest in uric acid contents $(2.44 \pm 0.06)$. As far as interaction is concerned, significant differences $(p<0.05)$ were observed among the treatment group. The chicks from large eggs under P5 regime had significantly highest uric acid contents $(4.27 \pm 0.10)$ at 35 days of age while those from the smaller eggs under PO presented the lowest contents of uric acid $(2.53 \pm 0.10)$ in their blood. There were significant differences in blood cholesterol level of the broilers from different egg weight categories $(p<0.05)$. Highest

Table 6 - Effect of egg weight and patio strategies on blood constituents of broilers.

\begin{tabular}{|c|c|c|c|c|c|c|c|}
\hline & $\begin{array}{l}\text { Glucose } \\
\mathrm{mmol} / \mathrm{L}\end{array}$ & $\begin{array}{c}\text { Total protein } \\
\mathrm{g} / \mathrm{dL}\end{array}$ & $\begin{array}{l}\text { Albumin } \\
\mathrm{g} / \mathrm{dL}\end{array}$ & $\begin{array}{l}\text { Globulin } \\
\text { g/dL }\end{array}$ & $\begin{array}{l}\text { Uric acid } \\
\mathrm{mg} / \mathrm{dL}\end{array}$ & $\begin{array}{c}\text { Cholesterol } \\
\mathrm{mg} / \mathrm{dL}\end{array}$ & $\begin{array}{c}\text { Creatinine } \\
\mathrm{mg} / \mathrm{dL}\end{array}$ \\
\hline \multicolumn{8}{|l|}{ Egg weight } \\
\hline Small & $13.34 \pm 0.42^{\mathrm{a}}$ & $3.02 \pm 0.06$ & $1.43 \pm 0.03^{\mathrm{ab}}$ & $1.59 \pm 0.07$ & $3.23 \pm 0.08^{b}$ & $124.08 \pm 2.14^{b}$ & $0.61 \pm 0.02$ \\
\hline Medium & $11.08 \pm 0.48^{b}$ & $3.14 \pm 0.07$ & $1.36 \pm 0.03^{b}$ & $1.79 \pm 0.08$ & $3.33 \pm 0.09^{b}$ & $130.03 \pm 1.69^{a}$ & $0.66 \pm 0.02$ \\
\hline Large & $13.63 \pm 0.52^{\mathrm{a}}$ & $3.03 \pm 0.06$ & $1.45 \pm 0.03^{a}$ & $1.57 \pm 0.07$ & $3.52 \pm 0.09^{a}$ & $130.91 \pm 1.82^{a}$ & $0.64 \pm 0.03$ \\
\hline$p$-value & $<0.0001$ & 0.3168 & 0.0402 & 0.0657 & 0.0005 & 0.0014 & 0.1637 \\
\hline \multicolumn{8}{|c|}{ Patio strategies } \\
\hline PO & $10.28 \pm 0.40^{b}$ & $3.00 \pm 0.07$ & $1.27 \pm 0.03^{b}$ & $1.73 \pm 0.08$ & $2.44 \pm 0.06^{d}$ & $115.68 \pm 1.81^{c}$ & $0.48 \pm 0.02^{c}$ \\
\hline P3 & $11.65 \pm 0.49^{b}$ & $3.07 \pm 0.07$ & $1.44 \pm 0.04^{a}$ & $1.63 \pm 0.08$ & $3.17 \pm 0.07^{c}$ & $121.63 \pm 1.79^{c}$ & $0.65 \pm 0.03^{b}$ \\
\hline P5 & $13.83 \pm 0.54^{a}$ & $3.10 \pm 0.08$ & $1.45 \pm 0.04^{\mathrm{a}}$ & $1.65 \pm 0.10$ & $3.76 \pm 0.07^{b}$ & $133.58 \pm 1.65^{b}$ & $0.68 \pm 0.03^{a b}$ \\
\hline P7 & $14.95 \pm 0.60^{a}$ & $3.09 \pm 0.07$ & $1.49 \pm 0.04^{a}$ & $1.60 \pm 0.08$ & $4.05 \pm 0.06^{a}$ & $142.45 \pm 1.81^{a}$ & $0.73 \pm 0.02^{\mathrm{a}}$ \\
\hline$p$-value & $<0.0001$ & 0.7445 & $<0.0001$ & 0.7186 & $<0.0001$ & $<0.0001$ & $<0.0001$ \\
\hline \multicolumn{8}{|l|}{ Interaction } \\
\hline Small×PO & $11.45 \pm 0.61^{\mathrm{def}}$ & $3.02 \pm 0.11$ & $1.35 \pm 0.04^{\text {cd }}$ & $1.67 \pm 0.13^{\mathrm{ab}}$ & $2.53 \pm 0.10^{f}$ & $107.45 \pm 2.85^{9}$ & $0.50 \pm 0.03^{e}$ \\
\hline SmallxP3 & $8.30 \pm 0.549$ & $2.86 \pm 0.13$ & $1.20 \pm 0.06^{d}$ & $1.66 \pm 0.16^{\mathrm{ab}}$ & $2.31 \pm 0.09^{f}$ & $120.15 \pm 3.00^{\text {ef }}$ & $0.60 \pm 0.03^{\text {cde }}$ \\
\hline SmallxP5 & $11.10 \pm 0.73^{\text {ef }}$ & $3.11 \pm 0.15$ & $1.25 \pm 0.06^{\mathrm{cd}}$ & $1.86 \pm 0.15^{\mathrm{ab}}$ & $2.49 \pm 0.10^{f}$ & $119.45 \pm 2.85^{e f}$ & $0.34 \pm 0.04^{f}$ \\
\hline Small×P7 & $11.85 \pm 0.55^{\text {cdef }}$ & $3.03 \pm 0.15$ & $1.42 \pm 0.05^{b c}$ & $1.60 \pm 0.15^{\mathrm{ab}}$ & $2.87 \pm 0.10^{e}$ & $113.05 \pm 2.39^{\mathrm{fg}}$ & $0.63 \pm 0.05^{\mathrm{bcd}}$ \\
\hline Medium $\times \mathrm{PO}$ & $9.70 \pm 0.78^{\mathrm{fg}}$ & $3.21 \pm 0.11$ & $1.62 \pm 0.06^{a}$ & $1.59 \pm 0.12^{\mathrm{ab}}$ & $3.11 \pm 0.09 \mathrm{e}$ & $122.05 \pm 2.39^{d e}$ & $0.56 \pm 0.05^{\mathrm{de}}$ \\
\hline Medium×P3 & $13.40 \pm 0.98^{\text {abcde }}$ & $2.99 \pm 0.09$ & $1.29 \pm 0.06^{\mathrm{cd}}$ & $1.70 \pm 0.13^{\mathrm{ab}}$ & $3.55 \pm 0.10^{d}$ & $129.80 \pm 3.33^{\mathrm{cd}}$ & $0.77 \pm 0.03^{a}$ \\
\hline Medium×P5 & $14.25 \pm 0.83^{\mathrm{abc}}$ & $2.86 \pm 0.10$ & $1.43 \pm 0.06^{b c}$ & $1.44 \pm 0.13^{a b}$ & $3.71 \pm 0.13^{\mathrm{cd}}$ & $134.65 \pm 3.11^{b c}$ & $0.58 \pm 0.03^{\mathrm{de}}$ \\
\hline Medium×P7 & $13.30 \pm 0.88^{\text {bcde }}$ & $3.39 \pm 0.16$ & $1.30 \pm 0.05^{\mathrm{cd}}$ & $2.08 \pm 0.17^{a}$ & $3.63 \pm 0.10^{d}$ & $138.75 \pm 2.61^{\mathrm{ab}}$ & $0.78 \pm 0.05^{a}$ \\
\hline LargexPO & $13.95 \pm 1.13^{\mathrm{abcd}}$ & $3.06 \pm 0.15$ & $1.63 \pm 0.06^{a}$ & $1.43 \pm 0.17^{a b}$ & $3.96 \pm 0.12^{b c}$ & $127.35 \pm 2.34^{\text {cde }}$ & $0.70 \pm 0.04^{\mathrm{abc}}$ \\
\hline LargexP3 & $15.80 \pm 0.96^{\mathrm{ab}}$ & $3.19 \pm 0.12$ & $1.53 \pm 0.07^{\mathrm{ab}}$ & $1.66 \pm 0.13^{\mathrm{ab}}$ & $3.81 \pm 0.11^{\mathrm{bcd}}$ & $141.15 \pm 3.19^{a b}$ & $0.74 \pm 0.03^{\mathrm{ab}}$ \\
\hline LargexP5 & $13.00 \pm 1.07^{\text {cde }}$ & $3.13 \pm 0.13$ & $1.30 \pm 0.06^{\mathrm{cd}}$ & $1.82 \pm 0.16^{\mathrm{ab}}$ & $4.27 \pm 0.10^{a}$ & $139.15 \pm 3.02^{b c}$ & $0.71 \pm 0.02^{\mathrm{ab}}$ \\
\hline LargexP7 & $16.05 \pm 1.02^{a}$ & $2.95 \pm 0.13$ & $1.64 \pm 0.04^{a}$ & $1.31 \pm 0.13^{b}$ & $4.08 \pm 0.09^{\mathrm{ab}}$ & $147.05 \pm 3.04^{a}$ & $0.75 \pm 0.04^{\mathrm{ab}}$ \\
\hline$p$-value & $<.0001$ & 0.0731 & $<0.0001$ & 0.0141 & 0.0008 & $<0.0001$ & $<0.0001$ \\
\hline
\end{tabular}

Different superscripts on within a column show significant differences. 
cholesterol levels (130.91 11.82) was noted in the birds from large eggs while the birds from the small eggs had the lowest cholesterol levels (124.08 \pm 2.14$)$. Significant effect of patio strategies was also evident on blood cholesterol showing higher value in the birds from $\mathrm{P7}$ group (142.45 \pm 1.81 ) followed by P5 (133.58 \pm 1.65$)$, P3 $(121.63 \pm 1.79)$ and the least value was recorded in P0 (115.68 \pm 1.81$)$. Concerning the interaction among egg weight categories and patio strategies, a significantly higher level of cholesterol (147.05 \pm 3.04$)$ was observed in large $\times$ P7 while the birds under Small $\times$ PO group showed the lowest cholesterol contents (107.45 \pm 2.85$)$ in their blood compared to the other treatment groups. Statistical analysis revealed no impact of egg weight on creatinine contents of the experimental birds ( $p>0.05$ ). The patio strategies resulted in significant differences $(p<0.05)$ among the treatments for blood creatinine of broilers. P7 strategy resulted in the highest creatinine $(0.73 \pm 0.02)$ while conventional P0 group had the lowest $(0.48 \pm 0.02)$ creatinine level. There were significant interactions among the egg weight and patio strategies for creatinine contents. The chicks from the medium eggs under P7 strategy had the highest level of creatinine in their blood $(0.78 \pm 0.05)$ while the least contents of creatinine $(0.34 \pm 0.04)$ were observed in small $\times$ P5 treatment.

\section{DISCUSSION}

\section{Hatch window}

Hatch window is an important criterion to assess the efficiency of the hatching process and to minimize the losses caused by post-hatch delayed feeding (Paul, 2015). In the current study, it was found that the small-sized eggs hatched more at $471 \mathrm{hrs}$ and took significantly less time for hatch completion compared to medium-sized eggs. Maximum hatchability was noted from small-sized eggs at 491 hours postplacement in the setter. However, medium and larger sized eggs took significantly more time than small-sized eggs even after 504 hours. These findings are in line with the previous reports of Ulmer-Franco et al. (2010) who reported that lightweight eggs took a hatching time of 498 hours that was significantly less than average-sized and heavy sized eggs. Various factors can influence the hatching time of the eggs and the breeder age is the most important one of them (Ipek \& Sozcu, 2015). The eggs from younger flocks contain more nutrient contents and there are more chances to obtain healthier chicks from these eggs which can easily manage their hatching process. On the other hand, older flocks are often deficient in essential vitamins and minerals that can hinder and delay the hatching process (Vieira, 2007; Calini \& Sirri, 2007). Possibly, the breeders' age had created a difference in total hatch time of the eggs under the study. This is the reason that the in-ovo practices are being applied to provide to feed for the chicks with essential micronutrients.

\section{Hatching traits}

Hatching traits are considered traits of economic importance for broiler breeders. The results of the present experiment showed a higher loss of weight in medium-sized eggs compared to large-sized eggs. Complementary reports were published earlier where lower egg weight loss was noted in larger eggs than medium eggs (Iqbal et al., 2016) and can be attributed to higher egg albumen and greater water contents in larger sized eggs. This suggested that the embryonic metabolism in different egg weights was different from each other. Generally, an equal amount of water is produced from yolk fat stores during embryonic development and the amount of water excreted is dependent on shell thickness, shell membranes, egg size and incubation conditions (Iqbal et al., 2016). However, the weight loss in small eggs was not significantly different from medium and large eggs ( $p>0.05)$. In terms of overall hatchability and fertility, medium-sized eggs were better than large eggs whereas the small eggs' hatchability and fertility were comparable to both the medium and large size eggs. This is similar to the findings of Duman \& Şekeroğlu (2017) who reported significantly higher hatchability in medium weight eggs than in larger sized eggs. Iqbal et al. (2016) reported higher fertility and hatchability in medium-sized eggs than in larger eggs. The hatch of fertile and embryonic mortality patterns (early, mid and late mortalities) were not different among the experimental egg weight groups ( $p>0.05)$. More number of culled chicks were observed from larger eggs than those from medium-sized eggs. Generally, the culled chicks are characterized by un-healed naval, week legs and other deformities. An earlier study from Duman \& Şekeroğlu (2017) reported similar results showing a higher percentage of deformed chicks from larger sized eggs compared to medium-sized eggs but small-sized eggs were comparable to both egg weight categories in terms of deformed/culled chicks. Our results showed that the proportion of chicks with no defect/healthy chicks was significantly higher in medium-sized eggs compared to the large eggs. Duman \& Şekeroğlu (2017) reported a significantly higher yield of healthy chicks from medium-sized eggs 
compared to that from the larger sized eggs. The initial weight of the chick was found to be significant among the egg weight categories $(p<0.05)$. Larger sized eggs produced significantly heavier chicks than the medium-sized eggs and the lowest chick weight was noted in the small-sized eggs. Our findings are in-line with previous studies where egg weight significantly affected the chick weight showing higher chick weight in the larger sized eggs (Ishaq et al., 2015; lqbal et al., 2016; Duman \& Şekeroğlu, 2017). Higher chick weight from the larger eggs could be due to higher residual egg yolk contents in the larger eggs compared to the medium and small eggs (Joseph et al., 2006; Ishaq et al., 2015).

\section{Post-hatch growth performance}

Feed intake of the broilers was significantly affected by egg size $(p<0.05)$. The birds from the small eggs consumed significantly less feed than those from the medium and large eggs. Iqbal et al. (2017) reported lower feed consumption in three-week-old male broilers from small eggs compared to those from medium and large-sized eggs. Ewonetu \& Kasaye (2018) showed higher feed intake in white leghorn from larger size eggs compared to those from smaller eggs. The feed intake is highly dependent on the physiological needs and body size of the birds. Lower intake in the birds from smaller eggs might be due to lower weight gain. However, some previous studies showed nonsignificant differences in the birds from different egg weight categories (Vieira \& Moran Jr, 1998; UlmerFranco et al., 2010). However, the chicks from smaller eggs reared under PO consumed significantly lower feed while highest feed intake was noted in the birds from the medium-sized eggs subjected to P5. Earlier to this, Proszkowiec-Weglarz et al. (2019) showed that post-hatch 48 hours of feed deprivation in broiler chicks resulted in significantly less intake compared to the birds having immediate access to the feed. The higher feed intake in P5 might be because the birds use this feed in body development including gastrointestinal tract (Lamot et al., 2014; Simon et al., 2014; Lilburn \& Loeffler, 2015). Bodyweight gain was significantly different in the chicks from different egg weight categories $(P<0.05)$. The birds from medium and medium-size eggs gained significantly higher weight than the birds from small size eggs. Similarly, Iqbal et al. (2017) reported significantly higher three-week body weight in broilers from larger size eggs compared to those from smaller eggs. In another study, Alabi et al. (2012) reported similar results showing higher weight gain in 7 weeks old Potchefstroom Koekoek chicks from the larger eggs compared to those from small eggs. This shows that the larger chicks obtained from larger eggs in this experiment maintained the advantage of their initial higher egg weight (Alabi et al., 2012). In the current experiment, the birds under P3 had significantly higher weight gain. Simon et al. (2015) reported higher body weight of the birds having access to the feed in the hatcher compared to those conventionally grown broilers. When the broiler chicks from medium-sized eggs were reared under P5, they presented the highest weight gain compared to those from small-sized eggs reared under conventional hatching. The lower weight gain in the chicks from smaller eggs might be due to small yolk reservoirs. The yolk sac is considered as the main source of nutrients for newly hatched chicks and its deficiency may lead to Ketosis and losses in live performance if chicks are subjected to prolonged fasting (Vieira \& Moran Jr, 1999).

Significantly different FCRs were noted among the birds from three egg weight categories. Overall FCR was better in the broilers from the mediumsized eggs followed by those from the smaller eggs and the poorest FCR was recorded for those from the larger eggs $(p<0.05)$. Similarly, $\mathrm{Ng}^{\prime}$ ambi et al. (2013) reported better FCR in the birds from the mediumsize eggs compared to those from the smaller eggs in indigenous chickens. Better FCR of birds from the medium-sized eggs can be attributed to higher weight gain. However, Duman \& Şekeroğlu (2017) showed similar values of FCR among the birds from small, medium and large size eggs in broilers. Regarding $F C R$, the birds under P3 were better followed by those under P5 and the poor FCR was noted in the birds under conventional hatching system i.e PO. The chicks from the medium-size eggs reared under P3 showed significantly better FCR whereas the birds from the larger eggs under PO exhibited the poorest FCR among all the possible interactions. Similar to our findings, de Jong et al. (2017) revealed that delayed feeding of chicks for 72-hour post-hatch resulted in higher FCR from hatch from day 0 to 42 . Contrary to our results, Hollemans et al. (2018) reported a non-significant effect of delayed feeding on the FCR of the broilers. de Jong et al. (2017) suggested that the exposure to exogenous feed in early 48 hours of the chick's life is important for the development of gastrointestinal tract that helps the chicks obtain better enzymatic activity and absorptive capacity. This might have led to better nutrient utilization and more weight gain ultimately resulting in better FCR of the early fed birds. 
Yameen RMK, Hussain J, Mahmud A, Saima
Effect of Egg Weight and Patio Strategies on Hatching Traits and Subsequent Performance of the Broilers

\section{Livability}

No effect of egg weight on livability in the current experiment is similar to the findings of Yousaf et al. (2018). However, patio strategies presented a higher survival rate in the birds under P5 followed by P3 and the least survival rate was recorded in the birds under P7. Findings of the present study are in-line with the report of de Jong et al. (2017) who performed a meta-analysis and reported that the feed and water deprivation up to 48 hours of post-hatch may lead to significantly higher total mortality than 0 or 24 hours feed and water post-hatch deprivation in broilers. Livability differed significantly when the interactions were evaluated among the egg weight categories and patio strategies. The survival rate was the highest in the chicks from the smaller eggs reared under P5 whereas higher mortality was noted in the chicks from the small egg size under P7 and P0. Early feeding had been reported to stimulate the development of immune organs such as gut associate lymphoid and hence a higher lymphocyte production can be expected (Bigot et al., 2001) which might have played a role to protect the birds in P5 group compared to P0. P7 birds were forced to stay in the hatcher section for a longer period than P5 and P3 which might have created a stressful situation due to little space and relatively poor ventilation in that section. It is suggested that a stay in the hatcher more than five days is not suitable for further performance and survival rate of the birds.

\section{Physical asymmetry and welfare traits}

Symmetric traits (relative as well as fluctuating asymmetry) are related to the welfare especially the gait score (Caplen et al., 2012) and compatibility of the birds to the environment. Under optimum environmental conditions, these traits grow symmetrically (Mitchell \& Kettlewell, 1998; Duman \& Şekeroğlu 2017). In the current experiment, physical asymmetry and gait scores did not differ among the chicks from different egg weight categories and patio strategies. Our findings suggest the absence of any environmental stress on the experimental birds as there was no difference in the asymmetry of the broilers. This might have led to similar gait scores among the treatment groups (Caplen et al., 2012).

The birds from larger eggs had significantly cleaner feathers than those from the medium-sized eggs that had dirty and damaged feathers and showed poor feather score. The broilers from the small and large size eggs under P7 had the cleaner feathers with adequate feather cover compared to any other treatment both showing the lowest feather scores. On the other hand, the birds from the medium-sized eggs under PO showed the poorest feather score. The data regarding the effect of early feeding on feather conditions is very limited. Although, we were unable to find the literature, however, feed restriction has been found to have a detrimental effect on feathers cover in broilers resulting in poor welfare. Chronic hunger may create stressful conditions for the birds leading to frustration, aggressive and abnormal behaviour and injurious feather pecking in chickens (De Jong \& Guemene 2011; Nicol et al., 2017).

\section{Blood biochemistry}

Statistical analysis showed a significant effect of egg weight and patio strategies on the blood glucose levels of broilers. Higher glucose contents were noted in the birds from large eggs while the lower glucose was observed in the blood of birds from medium eggs. However, Contrarily, Duman \& Şekeroğlu (2017) reported non-significant differences among the birds from light, medium and heavy eggs. Among the patio treatments, a significant effect was noted. Highest glucose in broilers was recorded in the chicks from the large eggs under P7. While small $\times$ P3 treatment presented the lowest glucose contents compared to any other experimental group. Similarly, van de Ven et al. (2011) reported significantly higher blood glucose in the chicks from patio systems compared to those under the conventional system. In another study, Wang et al. (2014) reported a significant effect of hatching time and early feeding on the glucose contents in broilers. This can be attributed to the increased level of corticosterone that possibly had increased gluconeogenesis in the chicks from the patio system as compared to the conventional hatcher (Joseph \& Ramachandran, 1992; Piestun et al. 2008).

Total protein contents were not affected by egg weight categories and patio strategies $(P>0.05)$ which is similar to the findings of Kang et al. (2018) who reported no effect of early feeding inside the hatcher on the total protein contents of broilers. Several factors affect the serum protein contents in chickens and of these, nutrition is the major one. Comparable serum protein in the current study could be attributed to similar crude protein in the diet of the experimental birds (Liu et al., 2015). However, in a previous study, significantly higher total protein contents were reported in the chicks accessing the feed within 4 hours of hatching than those who were provided feed after 24 and 48 hours post-hatch (Adeleye et al., 2018). 
There was a significant influence of egg weight and patio strategies on albumin contents of the broilers. The chicks from the larger eggs had significantly higher serum albumin compared to those from the medium eggs. P7 resulted in significantly higher albumin contents whereas the birds under PO were lowest in this parameter. However, contrary to our findings, the chicks provided with a pre-starter diet and those under conventional hatching did not differ in albumin contents in the blood (Abousekken et al., 2017).

The interaction of egg weight and patio strategies influenced the serum globulin contents which showed a significantly $(p<0.05)$ lower globulin values in chicks from larger eggs under P7 suggesting a better utilization of protein in the diet (Adeleye et al., 2018). This could be attributed to the size of the ova released from the ovary. Previously, it has been described that the maximum transport of gamma globulin per square centimetre of yolk surface occurs in smaller ova (Patterson et al., 1962). There was a significant effect of egg size and patio strategies on uric acid contents in blood. Among the egg categories, the birds from the larger eggs had significantly higher uric acid contents in their blood compared to those from the smaller eggs. In terms of patio strategies, P7 group presented the highest contents of uric acid while the birds from P0 were lowest in uric acid contents. In another study, the chicks that were offered feed 48 hours post-hatch presented significantly higher uric acid contents than those who were provided feed 4 hours after the hatching process (Adeleye et al., 2018). The chicks from the large eggs under the P5 regime had significantly highest uric acid contents at 35 days of age while those from the smaller eggs under PO presented the lowest contents of uric acid in their blood. Contrarily, in a previous study, patio hatching system resulted in comparable uric acid contents in newly hatched chicks to conventional hatching system (van de Ven et al., 2011). Regarding cholesterol, the highest cholesterol level was noted in the birds from the large eggs while the birds from the small eggs had the lowest cholesterol. Similarly, in earlier literature, a positive relationship between egg weight and cholesterol has been reported (Jiang \& Sim, 1991). Possibly, the breeder age was a factor that affected the egg weight and subsequently the cholesterol contents in the blood (Wilson, 1978). Significant effect of patio strategies was also obvious on blood cholesterol showing higher value in the birds from the P7 group followed by P5, P3 and the least value was recorded in PO. These findings suggested that the egg weight and early feeding in newly hatched chicks play an important role in modulating lipid metabolism. Contrary to our findings, cholesterol was not influenced by feed restriction in broilers (Afsharmanesh et al., 2016). A significantly higher level of cholesterol was observed in large $x$ P7 while the birds under Small $\times$ PO group showed the lowest cholesterol contents in their blood compared to the other treatment groups. However, Kang et al. (2018) were unable to find significant differences in the broilers under patio feeding regimes.

Creatinine is an important criterion to assess the muscle/protein catabolism. No impact of egg weight on creatinine was noted, but the patio strategies resulted in significant differences among the treatments for blood creatinine of broilers. P7 resulted in the highest creatinine while conventional PO group was the lowest in creatinine level of the broilers. In a previous report, significantly higher creatinine was noted in the birds offered feed 48 hours post-hatch compared to those who had access to the feed just after 4 hours posthatch (Adeleye et al., 2018). The chicks from medium eggs under P7 strategy were highest in their blood creatinine while the least contents of creatinine were observed in small $\times$ P5 treatment. This suggested that the muscle/protein catabolism was lowest when chicks from small eggs were provided feed for five days within the hatcher. Attia et al. (2017) suggested that the difference in the blood creatinine could be due to growth, duration and intensity of the feed restriction. Contrary to our findings, Attia et al. (2017) reported no difference in creatinine level of feed restricted and non-restricted slow-growing chickens.

\section{CONCLUSIONS}

From the discussion of the findings of the current study, it can be concluded that the egg weight is an important criterion that can affect most of the hatching traits, hatch window and overall subsequent performance of the broilers. The early feeding strategies have a significant role in broilers' life and affect body weight, FCR and body function especially the carbohydrates, protein and lipid metabolism. Selecting the medium size eggs for hatching and providing the chicks from these medium eggs within the hatcher for three days (Medium $\times$ PS3) could be the best strategy to obtain optimum performance of the broilers.

\section{CONFLICT OF INTEREST}

The authors declare that there is no conflict of interest. 
Effect of Egg Weight and Patio Strategies on Hatching Traits and Subsequent Performance of the Broilers

\section{ACKNOWLEDGEMENTS}

The authors are very grateful to the administration of the Department of Poultry Production for providing the facilities for conducting this research. The authors are very thankful to the University Diagnostic Lab, UVAS, Lahore, Pakistan, for helping with the biochemical analysis of the experimental birds.

\section{REFERENCES}

Abousekken MS, Shalash SM, Elabd NM, Essa HG. The effects of early posthatch nutrition on broiler performance. Egyptian Journal of Poultry Science 2017;37(3):747-760.

Adeleye OO, Otakoya IO, Fafiolu AO, Alabi JO, Egbeyale LT, Idowu OM. Serum chemistry and gut morphology of two strains of broiler chickens to varying interval of post hatch feeding. Veterinary and Animal Science 2018;5:20-25.

Afsharmanesh M, Lotfi M, Mehdipour Z. Effects of wet feeding and early feed restriction on blood parameters and growth performance of broiler chickens. Animal Nutrition 2016;2(3):168-172.

Alabi OJ, Ngambi JW, Norris D, Mabelebele M. Effect of egg weight on hatchability and subsequent performance of Potchefstroom Koekoek chicks. Asian Journal of Animal and Veterinary Advances 2012;7(8):718-25.

Archer GS, Shivaprasad HL, Mench JA. Effect of providing light during incubation on the health, productivity, and behavior of broiler chickens. Poultry Science 2009;88(1):29-37.

Bamelis F, Kemps B, Mertens K, De Ketelaere B, Decuypere E, DeBaerdemaeker J. An automatic monitoring of the hatching process based on the noise of the hatching chicks. Poultry Science 2005;84(7):1101-1107.

Bell DD, Weaver WD, North MO. Commercial chicken meat and egg production. Berlin: Springer Science \& Business Media 2002; p. 621798.

Bergoug H, Guinebretière M, Roulston N, Tong Q, Romanini CE, Exadaktylos $V$, et al. Relationships between hatch time and egg weight, embryo sex, chick quality, body weight and pododermatitis severity during broiler rearing. European Poultry Science 2015;79:1-10

Bigot K, Tesseraud S, Taouis M. The relation of egg weight to chick weight at hatching. Productions Animales 2001;14:219-30

Calini F, Sirri F. Breeder nutrition and offspring performance. Brazilian Journal of Poultry Science 2007;9(2):77-83.

Caplen G, Hothersall B, Murrell JC, Nicol CJ, Waterman-Pearson AE, Weeks $C A$, et al. Kinematic analysis quantifies gait abnormalities associated with lameness in broiler chickens and identifies evolutionary gait differences. PloS One 2012;7(7):e40800.

Careghi C, Tona K, Onagbesan O, Buyse J, Decuypere E, Bruggeman V. The effects of the spread of hatch and interaction with delayed feed access after hatch on broiler performance until seven days of age. Poultry Science 2005;84(8):1314-1320.

De Jong IC, Guemene D. Major welfare issues in broiler breeders. World's Poultry Science Journal 2011;67(1):73-82.

De Jong IC, van Riel J, Bracke MB, van den Brand H. A'meta-analysis' of effects of post-hatch food and water deprivation on development, performance and welfare of chickens. Plos One 2017;12(12):e0189350.
Decuypere E, Tona K, Bruggeman V, Bamelis F. The day-old chick: a crucial hinge between breeders and broilers. World's Poultry Science Journal 2001:57(2):127-138.

Duman, M, Şekeroğlu, A. Effect of egg weights on hatching results, broiler performance and some stress parameters. Brazilian Journal of Poultry Science 2017;19(2):255-262

Ewonetu KS, Kasaye A. Effect of egg weight on post-hatch performance of white leghorn chicken breed from day-old to laying age. Tavukçuluk Araştırma Dergisi 2018;15(2):16-22.

Gonzales E, Kondo N, Saldanha ES, Loddy MM, Careghi C, Decuypere E. Performance and physiological parameters of broiler chickens subjected to fasting on the neonatal period. Poultry Science 2003;82(8):12501256.

Hollemans MS, de Vries S, Lammers A, Clouard C. Effects of early nutrition and transport of 1-day-old chickens on production performance and fear response. Poultry Science 2018;97(7):2534-2542.

Ipek A, Sozcu AR. The effects of broiler breeder age on intestinal development during hatch window, chick quality and first week broiler performance. Journal of Applied Animal Research 2015;43(4):402-408.

Iqbal J, Khan SH, Mukhtar N, Ahmed T, Pasha RA. Effects of egg size (weight) and age on hatching performance and chick quality of broiler breeder. Journal of Applied Animal Research 2016;44(1):54-64.

Iqbal J, Mukhtar N, Rehman ZU, Khan SH, Ahmad T, Anjum MS, et al. Effects of egg weight on the egg quality, chick quality, and broiler performance at the later stages of production (week 60) in broiler breeders. The Journal of Applied Poultry Research 2017;26(2):183-91.

Ishaq HM, Akram M, Baber ME, Jatoi AS, Sahota AW, Javed K, et al. Chick quality of Hubbard broiler breeders train with three different egg weights and storage periods at four production phases. Journal of Animal and Plant Sciences 2015;25(1):37-44

Jiang Z, Sim JS. Egg cholesterol values in relation to the age of laying hens and to egg and yolk weights. Poultry Science 1991;70:1838-1841.

Joseph J, Ramachandran AV. Alterations in carbohydrate metabolism by exogenous dexamethasone and corticosterone in post-hatched white leghorn chicks. British Poultry Science 1992;33(5):1085-1093.

Joseph NS, Lourens A, Moran Jr ET. The effects of suboptimal egg shell temperatureduring incubation on broiler chick quality. Poultry Science $2006: 85 \cdot 932-938$

Kang HK, Bang HT, Kim CH, Jeon JJ, Kim HS, Suh SW, et al. Effects of early feeding time post-hatch on growth, organ development, and blood biochemical profile in broiler chickens. Canadian Journal of Animal Science 2018;99(2):418-424

Lamot DM, Van De Linde IB, Molenaar R, Van Der Pol CW, Wijtten PJ، Kemp B, et al. Effects of moment of hatch and feed access on chicken development. Poultry Science. 2014;93(10):2604-2614.

Lilburn MS, Loeffler S. Early intestinal growth and development in poultry. Poultry Science 2015;94(7):1569-1576.

Liu SK, Niu ZY, Min YN, Wang ZP, Zhang J, He ZF, et al. Effects of dietary crude protein on the growth performance, carcass characteristics and serum biochemical indexes of Lueyang black-boned chickens from seven to twelve weeks of age. Brazilian Journal of Poultry Science 2015;17(1):103-108.

Mitchell MA, Kettlewell PJ. Physological stres and walfare of broiler chickens in transit: solutions not problems. Poultry Science 1998;77(12):18031814 
Yameen RMK, Hussain J,

Mahmud A, Saima
Effect of Egg Weight and Patio Strategies on Hatching Traits and Subsequent Performance of the Broilers
Ng'ambi JW, Thamaga MW, Norris D, Mabelebele M, Alabi OJ. Effects of egg weight on hatchability, chick hatch-weight and subsequent productivity of indigenous Venda chickens in Polokwane, South Africa. South African Journal of Animal Science 2013;43(5):S69-74.

Nicol CJ, Bouwsema J, Caplen G, Davies AC, Hockenhull J, Lambton $\mathrm{SL}$, et al. Farmed bird welfare science review. Agriculture in Vitoria. Department of Economic Development, Jobs, Transport and Resources; 2017. Available from: http://agriculture.vic.gov.au/_data/assets/pdf_ file/0019/370126/Farmed-Bird-Welfare-Science-Review-Oct-2017.pdf .

Olutunmogun AK, Umar AU, Adejoh-Ubani EO, Nwagu BI, Adeyinka IA, Muhammad SM. Effect of egg size and lines on hatching performance of chicks from broiler breeders under selection. Nigarian Journal of Animal Production 2018;45(1):18-25.

Patterson R, Youngner JS, Weigle WO, Dixon FJ. The metabolism of serum proteins in the hen and chick and secretion of serum proteins by the ovary of the hen. The Journal of General Physiology 1962;45(3):501513.

Paul MA. Effects of post-hatch holding time and early nutrition strategies on growth performance, carcass and skeletal characteristics of young chickens [thesis]. Lexington (EUA): College of Agriculture, the University of Kentucky; 2015.

Piestun Y, Shinder D, Ruzal M, Halevy O, Yahav S. The effect of thermal manipulations during the development of the thyroid and adrenal axes on in-hatch and post-hatch thermoregulation. Journal of Thermal Biology 2008;33(7):413-418

Proszkowiec-Weglarz M, Schreier LL, Miska KB, Angel R, Kahl S, Russell B. Effect of early neonatal development and delayed feeding posthatch on jejunal and ileal calcium and phosphorus transporter genes expression in broiler chickens. Poultry Science 2019;98(4):1861-1871.

Saxena VK, Kolluri G. Selection methods in poultry breeding: from genetics to genomics. In: Liu X. Application of genetics and genomics in poultry science. London: Intech Open; 2018

Simon K, de Vries Reilingh G, Bolhuis JE, Kemp B, Lammers A. Early feeding and early life housing conditions influence the response towards a noninfectious lung challenge in broilers. Poultry Science 2015;94(9):2041-2048.

Simon K, de Vries Reilingh G, Kemp B, Lammers A. Development of ileal cytokine and immunoglobulin expression levels in response to early feeding in broilers and layers. Poultry Science 2014;93(12):3017-3027.

Statista. Production of meat worldwide from 2016 to 2019, by type (in million metric tons). 2019. Available from: https://www. statista.com/statistics/237632/production-of-meat-worldwidesince-1990/\#: : text=Global \%20production $\% 20$ of $\% 20$ meat $\% 20$ 2016\%2D2019\%2C\%20by\%20type\&text=This \%20statistic\%20 projects $\% 20$ the $\% 20$ production, to $\% 2070.4 \% 20$ million $\% 20$ metric\%20tons.

Tong Q, Demmers T, Romanini CE, Bergoug H, Roulston N, Exadaktylos $\mathrm{V}$, et al. Physiological status of broiler chicks at pulling time and the relationship to duration of holding period. Animal 2015;9(7):11811187.

Ulmer-Franco AM, Fasenko GM, O'Dea Christopher EE. Hatching egg characteristics, chick quality, and broiler performance at 2 breeder flock ages and from 3 egg weights. Poultry Science 2010;89(12):2735-2742.

Van de Ven LJ, Van Wagenberg AV, Debonne M, Decuypere E, Kemp B, Van Den Brand $\mathrm{H}$. Hatching system and time effects on broiler physiology and posthatch growth. Poultry Science 2011;90(6):1267-1275.

Van de Ven LJ, Van Wagenberg AV, Decuypere E, Kemp B, Van Den Brand $\mathrm{H}$. Perinatal broiler physiology between hatching and chick collection in 2 hatching systems. Poultry Science 2013;92(4):1050-1061.

Van de Ven LJ, Van Wagenberg AV, Groot Koerkamp PW, Kemp B, Van den Brand $\mathrm{H}$. Effects of a combined hatching and brooding system on hatchability, chick weight, and mortality in broilers. Poultry Science 2009;88(11):2273-2279.

Vieira SL, Moran Jr ET. Broiler chicks hatched from egg weight extremes and diverse breeder strains. Journal of Applied Poultry Research 1998; 7(4):392-402.

Vieira SL, Moran Jr ET. Effects of egg of origin and chick post-hatch nutrition on broiler live performance and meat yields. World's Poultry Science Journal 1999;55(2):125-142.

Vieira SL. Chicken embryo utilization of egg micronutrients. Brazilian Journal of Poultry Science 2007;9(1):1-8.

Wang Y, Li Y, Willems E, Willemsen H, Franssens L, Koppenol A, et al. Spread of hatch and delayed feed access affect post hatch performance of female broiler chicks up to day 5. Animal 2014;8(4):610-717.

Wilson SC. Relationship between plasma concentration of luteinising hormone and intensity of lay in the domestic hen. British Poultry Science 1978;19:643-650.

Yousaf A, Rajput N, Memon AU, Jagirani GN, Shahnawaz R, Rajpar S,et al. Effect of hatch window upon intestinal development, chick quality, post hatch performance according to Ross308 broiler breeder age. Journal of Dairy and Veterinary Animal Research 2018;7(6): 293-297. 
